\title{
Using Reflection to Facilitate Writing Knowledge Transfer in Upper-Level Materials Science Courses
}

\section{Dr. Jennifer C. Mallette, Boise State University}

An Assistant Professor of English at Boise State University, Dr. Jenn Mallette teaches technical communication at the undergraduate and graduate level. In addition to working with STEM students in her undergraduate technical communication course, she collaborates with faculty in the College of Engineering to focus on enhancing writing education in engineering courses. Her other research focuses on women engineering, and she has recently published the results of a case study exploring the connections among women's experiences in engineering, their identities as writers, and their writing.

Harold Ackler P.E., Boise State University 


\section{Using Reflection to Facilitate Writing Knowledge Transfer in Upper-Level Materials Science Courses}

\section{Introduction}

When students enter upper-level engineering courses, they may bring with them unclear or inconsistent approaches to writing in engineering. Influenced by their past experiences with writing, students encountering engineering genres such as reports and proposals may struggle to write successfully [1]. They may struggle in part because of the messiness inherent in writing knowledge transfer: a student who successfully completed freshman composition may still be unable to transfer skills, habits of mind, and approaches to writing from that setting to engineering because the rhetorical situations look drastically different [2].Yancey, Robertson, and Taczak define transfer as a "dynamic rather than a static process, a process of using, adapting, repurposing the old for success in the new," and they argue that reflection-reflection that allows students to develop metacognition and a robust theory of writing - is integral to transfer [2]. In addition, for learning to take place and successful transfer to occur, students need to recognize what they don't yet know [2].

With an eye toward asking students to develop an engineering-specific theory of writing and nudging them into the novice status needed to learn how to address writing in a new context [2], we (Jenn Mallette, a faculty member in English/technical communication, and Harold Ackler, a faculty member in materials science and engineering) approached the writing components in junior- and senior-level materials science lab/project classes with two goals: 1.) asking students to engage in reflection throughout the semester to connect learning not only from prior classes, but across assignments, semesters, and years; and 2.) encouraging students to generate their own theory of writing that will help them address the demands of writing for engineering within school and beyond.

\section{Context}

The students in this study are juniors enrolled in a two-semester sequence of advanced materials science and engineering (MSE) project-based courses (MSE 380 and 381) at Boise State University. In MSE 380 and 381, the projects and writing assignments are designed to prepare them to succeed in the workplace. By the junior year, they have taken first-year writing (or earned credit) and two or more freshman and sophomore-level MSE courses with some technical and nontechnical writing components. However, they are not required to take the sophomorelevel, introductory technical communication course offered by the English department, unlike other engineering majors. MSE students find the laboratory writing assignments are significantly more complex and rigorous than any they have experienced to that point, creating a challenging transition in their junior and senior years.

Because of these writing challenges, in 2017, Jenn and Harold began working together to design approaches to working with both groups of students. For the juniors, we designed writing instruction and assignments on a scaffold throughout both courses. We first built a foundation through lectures and in-class activities and then added progressive skills with elements of technical writing; these elements were then extended in the senior year. However, many students had difficulty forming connections between projects and effectively transferring writing skills from assignment to assignment and/or course to course. To improve their understanding of the 
writing process, reflections were assigned at the beginning and end of the courses and after every assignment to provide opportunities to connect and apply learning across assignments and classes.

Following the junior lab courses, these students will enter the one-year senior capstone sequence, with Harold as lead instructor and Jenn continuing to work with them on writing through more hands-on methods such as writing workshops and direct feedback. The seniors spend the year working on projects for external sponsors, and the writing is intended for such audiences. Reflections have also been used in the senior year to continue building on their writing knowledge and to prepare them for writing beyond the university.

\section{Literature Review}

Reflection has long been an element of both writing and engineering education, particularly as a tool to increase learning and to provide opportunities to develop metacognition, both of which were goals in the MSE courses. Research in Writing Across the Curriculum/Writing in the Disciplines (WAC/WID) has taken up the use of reflection to support students' content learning in STEM e.g. [3], [4]. In engineering contexts, research has examined reflection as a tool for meaning-making and developing metacognition e.g. [5] - [7]. Research also tends to concentrate on using reflections (or reflective surveys) as a research tool to capture information about students' experiences in engineering, such as in their first year [8], around gender issues [9], or their use of textbooks to solve problems [10]. Other studies focus on the impact of reflection on engineering educators and their teaching practices [11] or development as educators [12].

Several studies examine reflection in the context of teaching design: one recommends using "structured reflection grounded in variation theory" to increase students' metacognition of their approaches to design work [13], and another includes reflection as an approach to systematically teach design methods [14]. Another used reflection through interviews to assess students' experiences around human-centered design and found that students learned more about themselves and human-centered design from the process, though it was not the focus of the study [15]. Thus, while some research in engineering education attempts to assess the impacts of reflection on student learning, many studies use a version of reflection as a research methodology (or as an outcome from research). Furthermore, researchers and educators understand the impact of reflection on student learning as a well-documented pedagogical tool, but little work seems to connect reflection to writing pedagogy in engineering contexts.

For the studies that do focus on reflection as a tool in classroom instruction, many of these studies focus on the impacts of reflection in lower-level introductory courses within the context writing to learn or WAC/WID, or they do not integrate the scholarship in composition studies toward considering reflection's role in writing education and its impact on knowledge transfer, particularly writing. In fact, one study notes that engineering education has not widely taken up reflection in research, though a large body of scholarly inquiry demonstrates the potential uses and impacts of reflection for engineering education [7], and it emerges as a recommendation or a subject for further investigation in pedagogical settings [13], [15]. However, in the context of best practices to support writing development, reflection emerges as a key pedagogical practice. In fact, at Boise State University, one of the outcomes for first-year writing is related to 
reflection [16]; Boise State's Center for Teaching and Learning also uses reflection as a core value [17].

Scholarship in writing studies has long explored the impacts of reflection in the writing classroom, and these studies influenced our use of reflections to provide a space for students to theorize about writing and to make connections. Although frequently used in the writing classroom and as a methodology, the field itself does not always use a consistent definition for what it calls reflection [18]. Yancey remarks that "[o]ne often undervalued and little understood method of identifying what we know and of understanding how we come to know involves what...has been called reflection" [19]. She goes on to define reflection as "1.) the process by which we know what we have accomplished and by which we articulate accomplishment and 2) the products of those processes (e.g., as in, 'a reflection')" [19]. She also notes that reflection requires both "looking forward to goals we might attain, as well as casting backward to see where we have been" [19], emphasis in original. Hsu notes that in their classes, "students used the term reflection as an ambiguous catchall, which stood for a wide variety of specific, rhetorical moves that connect individual stories with social exigences" [20], emphasis in original. Other researchers focus specifically on the narrative aspects (and identity-building potentials) of reflection, e.g. [20], and the uses can be for personal understanding and/or for public critique. However, despite the ambiguity of the term and its uses in both writing studies and engineering settings, reflection offers an avenue for students to construct knowledge and make connections and for instructors to get a glimpse into student experiences. Thus, reflection, integral to writing contexts, offers potentials for students to better understand not only themselves but also what they know and how to use it in other settings.

Finally, research on knowledge transfer highlights a number of directions for teachers and researchers [2]. These directions are promising for what we want our students to be able to do: transfer what we are teaching into other classes and beyond the university. One study looks at curricular design in first-year writing that facilitates transfer across contexts - the researchers' goal is to allow students "to participate with us in creating their own frameworks for facilitating transfer," and they ask what role reflection functions in creating opportunities for successful transfer [2]. Their study compares several types of composition classes to determine what influences transfer, finding the course developed from research on transfer that purposefully taught key terms demonstrated the most promise for facilitating transfer from first-year writing to other settings. They find "students need a vocabulary for writing in order to articulate knowledge and ensure more successful transfer" [2]. One component in this transfer is the use of reflection, since reflection may help students articulate a theory of writing that will allow them to transfer concepts from setting to setting and develop metacognition to understand how writing situations vary.

In this paper, we explore the possibilities of using reflections (or reflective exercises) in an engineering context to increase students' metacognition about writing and support writing transfer, particularly in upper-level courses. These reflections were focused on giving the students a chance to reflect on past experiences and project forward, as Yancey recommends [19]; in addition, the reflections provide a source of data for us to assess our classroom practices and identify areas to revise. While these findings are preliminary-we have yet to determine how much they've transferred-we explore the possibilities of using reflection in an engineering 
setting to help students reflect on the past and project to the future. In addition, given that this project emerges from a collaboration between English/technical communication and materials science faculty members, we highlight the ways this partnership not only improves student experiences around writing but enables a more dynamic research process.

\section{Method}

To gather data about students' interactions with their writing in the junior-level project class, we asked them to complete three types of reflections: overview reflections for the start and end of semester, learning reflections after class sessions with the English faculty member, and reflections (or debriefings) after submitting major written projects. See Table 1 for a summary of the types, the dates completed, and the number of students completing the reflections.

\section{Table 1. Junior-level reflections completed}

\begin{tabular}{|l|l|l|l|}
\hline Type of reflection & Project/Topic & Date completed & $\begin{array}{l}\text { Number of students } \\
\text { completed }\end{array}$ \\
\hline Overview & Start of semester & 30 August 2018 & 26 \\
\hline Overview & End of semester & 14 December 2018 & 23 \\
\hline Learning reflection & Reports & 14 September 2018 & 21 \\
\hline Learning reflection & Process and Style & 28 September 2018 & 22 \\
\hline Learning reflection & Proposals & 19 October 2018 & 17 \\
\hline Debriefing & Design report draft & 12 October 2018 & 13 \\
\hline Debriefing & Final design report & 9 November 2018 & 22 \\
\hline Debriefing & $\begin{array}{l}\text { Mini-project proposal } \\
\text { draft }\end{array}$ & 14 November 2018 & 23 \\
\hline
\end{tabular}

In the senior-level project class, students did fewer reflections overall, completing a start of semester reflection and debriefings after the major project phases, completing a total of five reflections: an overview for the start and end of semester, and three debriefings for their cover letter, problem statement, and full proposal.

The reflections were part of the course and encouraged students to think about their writing experiences, what successes they had, and what challenges they still faced. They also generally asked students to think back on their learning and successes for a given project and look forward at what they might do differently for the next written assignment. See Appendix A for specific questions.

After the fall semester concluded, reflection responses were downloaded from Google Forms into Excel. In addition to calculating the mean and standard deviation for the quantitative responses in the end of semester reflection, we coded the reflections for keywords or concepts 
the students used in their replies. These codes allow for trends and patterns to be examined across the reflections and to understand the narratives students created about their writing experience and knowledge.

\section{Results}

This discussion will be limited to the data from the start and end of semester reflections and surveys from the juniors to fit within the scope of this proceedings paper. In doing so the most common effects of the project on student writing may be discussed more thoroughly. Students' initial thoughts and perceptions of their writing are captured in Figures 1-4, which present results from the start and end of semester reflections side by side for a subset of the questions posed. The number of responses is listed above in Table 1.

Figures 1A and 1B show the top one to three writing concepts students thought about while writing at the start of the semester $(1 \mathrm{~A})$ and the concepts the report having learned by the end of the semester (1B). At the start more than half (14 out of 26) think about concise writing, followed by clear writing and good word choice. The "active voice," organization, structure, and a thesis were of concern to approximately $17 \%$ of students. At the end of the semester about half of the respondents (11 of 23) report learning to be more concise. Note the changes in ranking of concepts and the inclusion of more formal writing concepts at the end of the semester, which may indicate that students are now working with the formal concepts.
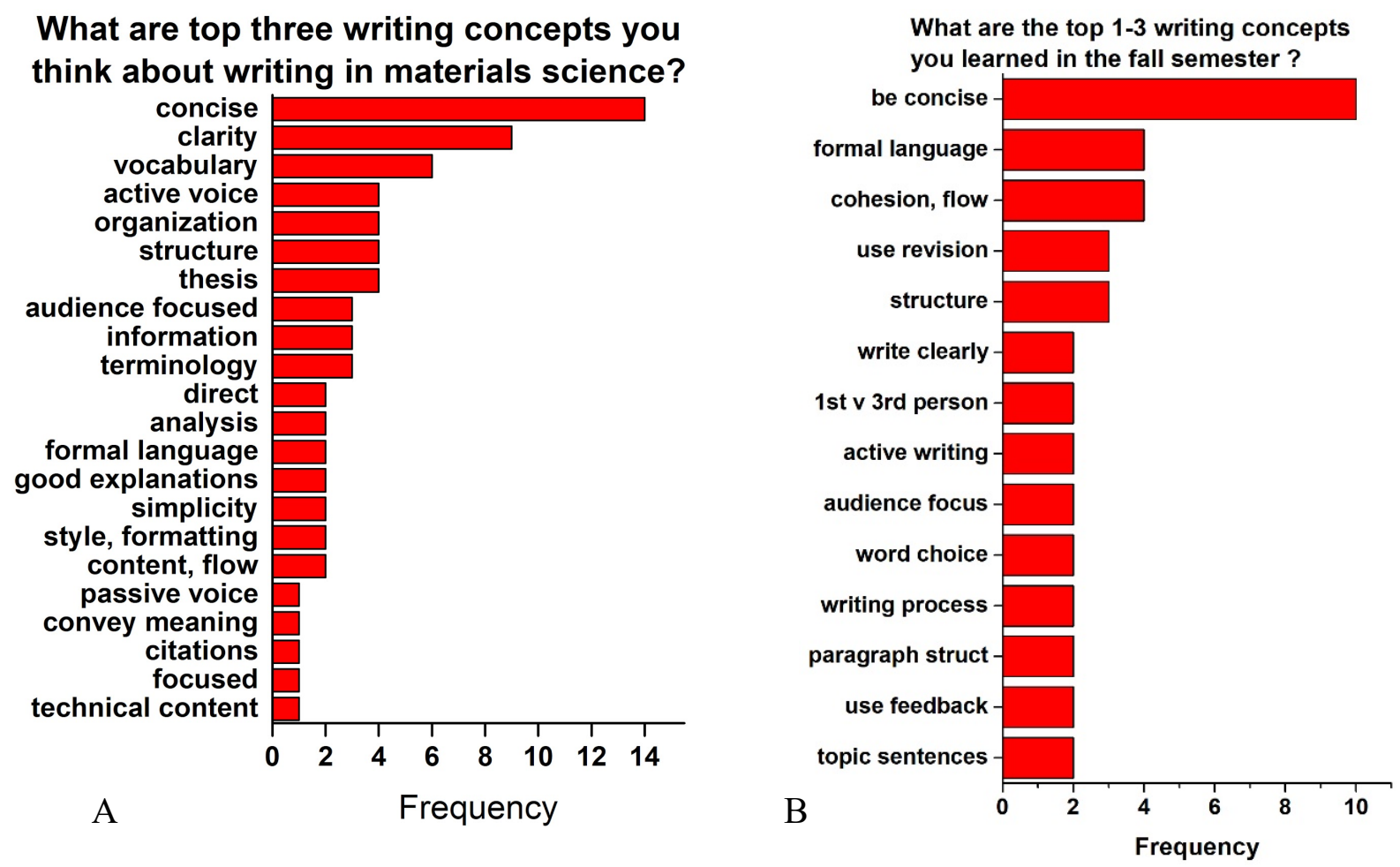

Figure 1. Top 1-3 writing concepts students think about when writing in materials science at (A) the start of and (B) the end of the fall semester. 
Figures 2A and 2B present students' perceived writing strengths at the start (2A) and the end (2B) of the semester. At the start of the semester "good explanations" and being concise were the most reported strengths (about $25 \%$ of students), followed by a focus on detail and vocabulary with 4 out of 26 responses. Audience focus, clarity, and grammar were reported by 3 out of 26 students. At the end concise writing (5 out of 23) and "good content" (4 out of 23) were most common. Structure and "writing about data" were reported by 3 out of 23 . Differences between the start and end of the semester include fewer types of strengths, and lower total reported strengths. For example, individual students must have reported multiple strengths at the start but reported fewer at the end. In addition, note that "grammar" does not appear at the end, which reflects the focus on higher-order writing concepts throughout the semester.
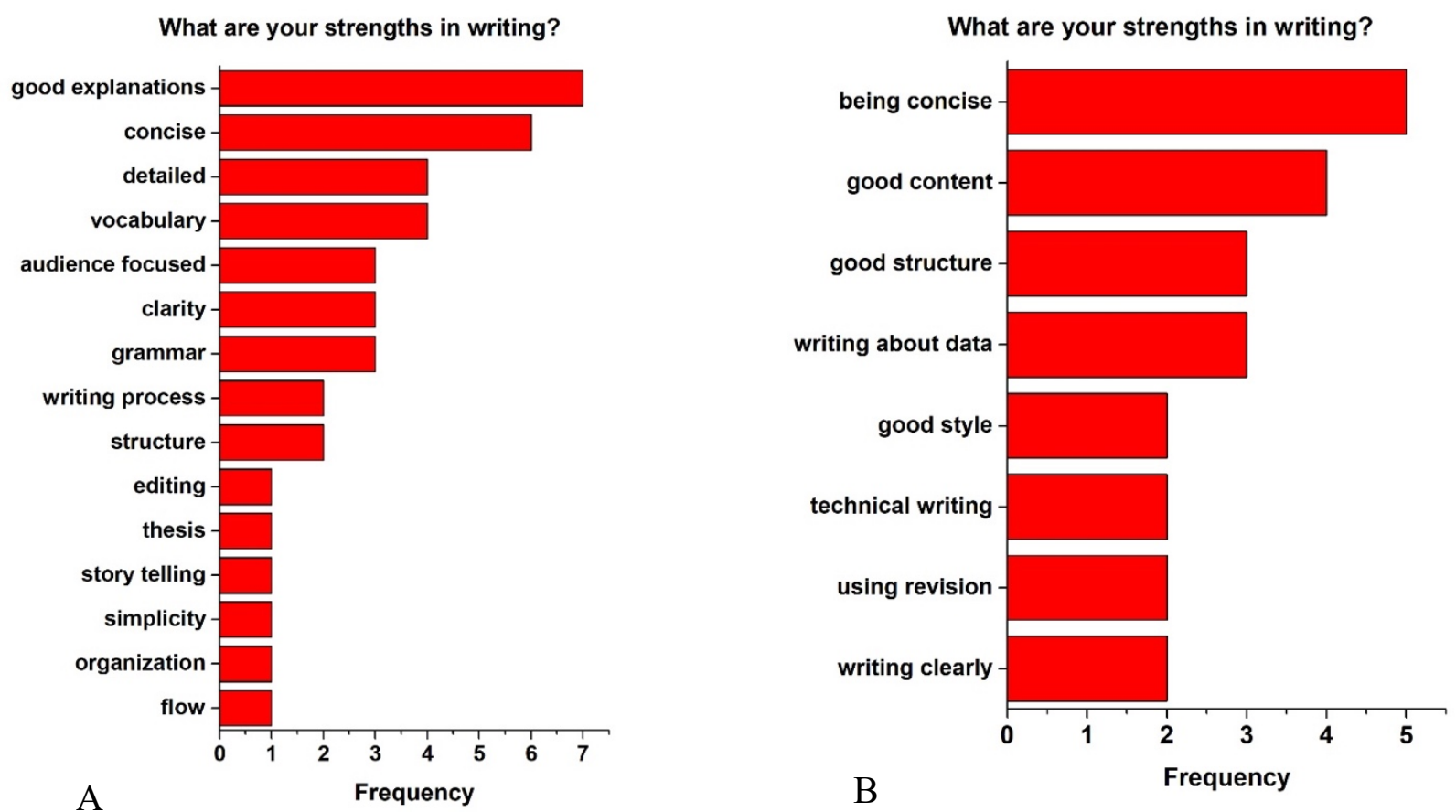

Figure 2. Students perceived strengths in writing at (A) the start of and (B) the end of the fall semester.

These strengths may be compared to their perceived challenges in writing in Figure 3 . Here the most common challenges were being concise and use of the writing process, which includes the practice of drafting, revising, and editing. Data counted for "writing process" may have only listed revision, editing, or both. The only other single concepts listed as challenges were including the appropriate quantity of information and creating flow. It is noteworthy that the same number of students at the start listed concise as a strength (6 out of 26) and a challenge (6 out of 26), yet only 5 students out of 23 listed it as a strength at the end. 


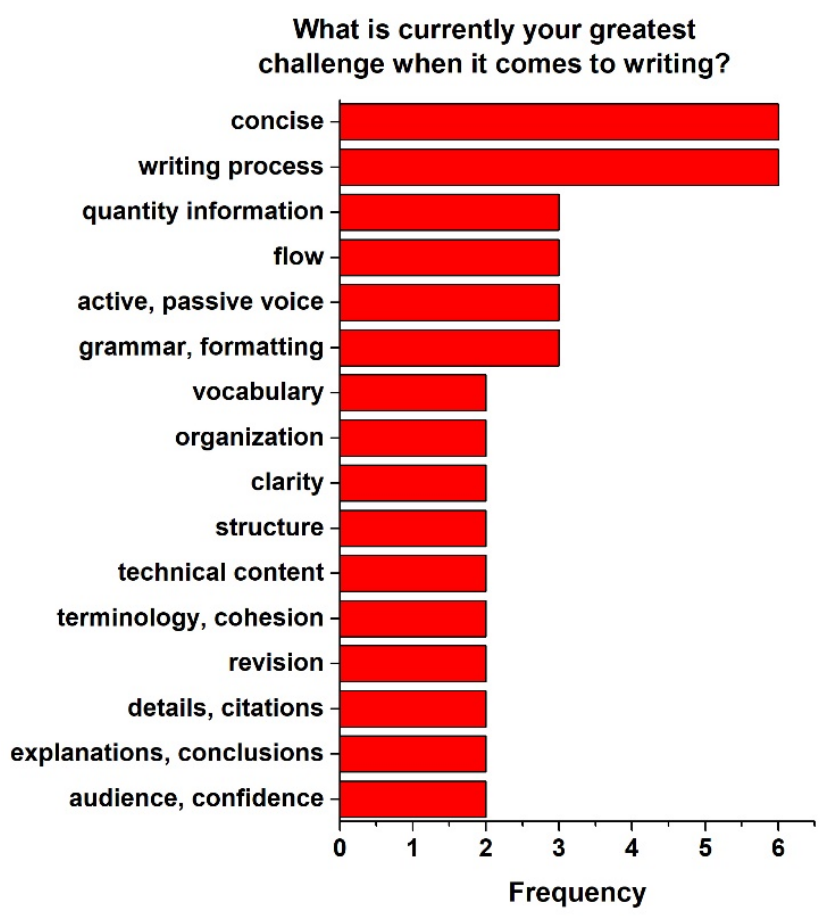

Figure 3. Students' perceived challenges in writing at the start of the fall semester.

However, by the end of the semester only one student reported overcoming a challenge and only $25 \%$ reported a challenge improving, as shown in Table 2 .

Table 2. Number of students reporting start of semester challenge still a challenge at the end

\begin{tabular}{|l|l|}
\hline Response & Number reporting \\
\hline Yes & 18 \\
\hline Improving & 6 \\
\hline No & 1 \\
\hline Maybe & 1 \\
\hline
\end{tabular}

Goals for writing reported at the start of the semester are shown in Figure 4. Most expressed interest in learning to "write effectively," "write well," and a few to be more concise, efficient, and learn to use a formal writing process. Note that fewer students listed being more concise as a goal than listed it as a challenge. 


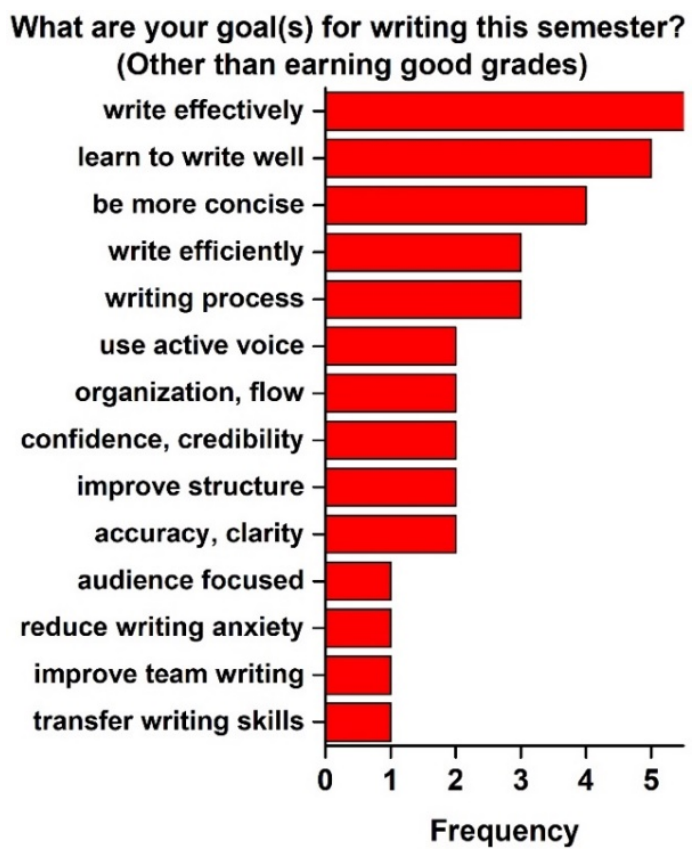

Figure 4. Students' goals for writing at the start of the fall

Their initial goals may be compared with what they recalled were their initial goals at the end of the semester in Figure 5A. At the end, the most reported goal (7 out of 23) was improving technical writing as their primary rather than "write more effectively" and "learn to write well," with "being more concise" and improving structure (sentences, paragraphs, and documents) at 3 out of 23. The change to improving technical writing may be due to better understanding of the terminology and concepts of technical writing.
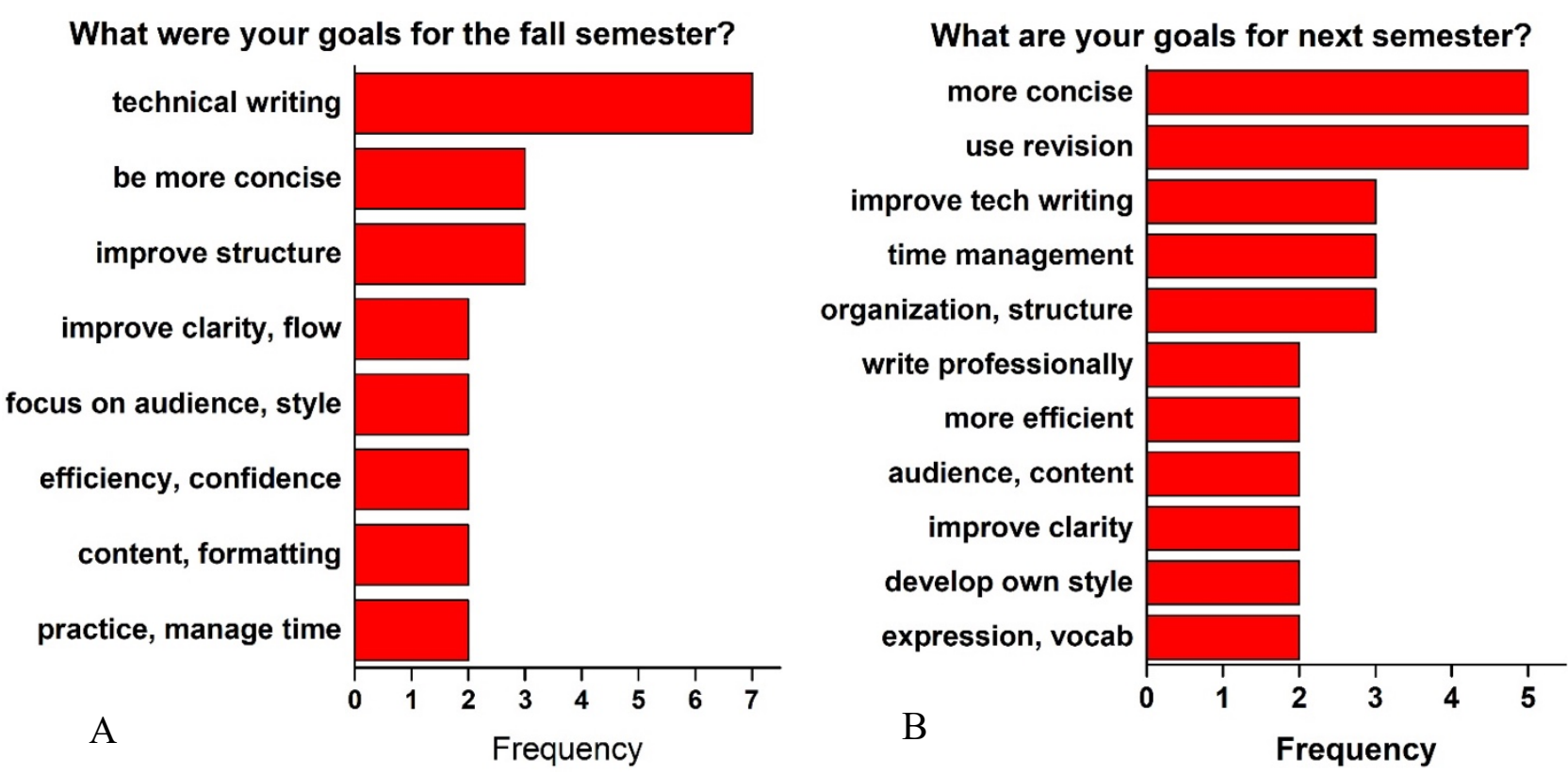

Figure 5. Students (A) recalled goals for writing at the start of the fall semester and (B) their goals for the following semester. 
Goals for the following semester are shown in Figure 5B for comparison. At the end of the semester "being more concise" was again at the top (5 out of 23) but now using revision was as well. "Improving technical writing," "time management," and organization and structure of writing were each reported by 3 out of 23 students. The reporting of revision, or the writing process and time management (most commonly "start earlier") show these concepts are now at the forefront of many students' minds as skills worth the effort to improve.

In addition to coding student responses on the surveys, the distribution of answers was calculated for the quantitative questions on the end of semester reflections for both the juniors and seniors. See Figure 6 for a comparison of the junior's rankings of three elements: how they viewed writing concepts, revision, and feedback as helpful to their writing education throughout the semester. The questions in the quantitative portion asked them to rank or rate their learning or understanding of writing concepts generally, use of revision, and use of feedback (as well as understanding of specific concepts), with 5 being "very helpful" to 1 being "not helpful at all." Generally, students felt that the focus on writing was helpful, with most of the answers clustering in the 4 and 3 responses; no one marked that any concept was not helpful at all (1) and very few marked elements as only somewhat helpful (2).

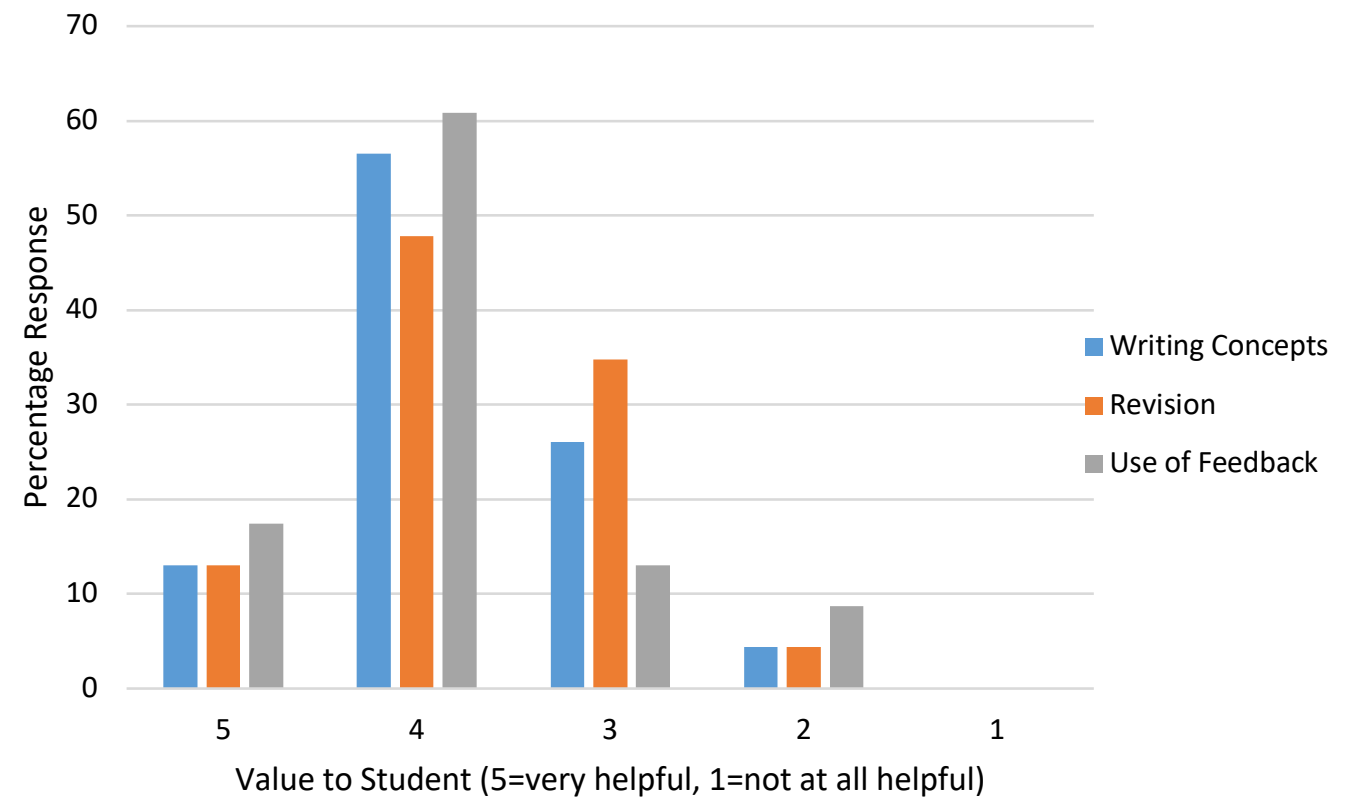

Figure 6. Juniors ranking of writing elements discussed in class, specifically focusing on general writing concepts, revision, and use of feedback (out of 23 responses)

All together, these data form a sense of what students took away from just one semester. In addition, they point to potential directions for the future as we continue to use reflection and integrated writing instruction to support their writing development.

\section{Discussion}

One of the strengths of the collaboration between Jenn (English/technical communication) and Harold (materials science) is what each brought to not only the project design but the data analysis as a whole. Jenn's knowledge of writing and transfer in writing studies influenced the use of reflections and what questions to have students answer, including using the three 
processes Yancey outlines (setting goals, revising texts, and stating learning) [19]. However, questions were also shaped by what the materials science faculty was interested in terms of the relationships between writing and learning technical concepts (related to a write-to-learn framework often used in WAC studies).

In addition, the data analysis and discussion here also reflect the strengths of this dynamic. While Jenn is stronger with qualitative research methods and analysis and familiar with the narratives students build around writing in STEM disciplines, Harold was able to think about how to bring a quantitative framework to analyze the data. This research process also reflects our teaching collaboration as we each contributed our expertise to benefit student learning; we also actively learn from each other about writing, student experiences, and disciplinary knowledge. This learning is only possible because of the sustained collaboration over years (rather than briefly in a semester) as well as each faculty member's curiosity and interest in work outside of our individual disciplines. Also essential to the success of this collaboration is that we are both willing to listen actively to each other and to our students. Subsequently, this project highlights the advantages of multidisciplinary collaborations and extended partnerships between faculty members from different backgrounds with shared goals.

The benefits of this partnership are also indicated in the data. Since students experienced a sustained focus on writing (and getting feedback as a result), they spent time trying recommendations and working to apply their learning to their writing. As the semester progressed, students began talking more about audience and the ways they considered audience, as shown in Figure 1B, where students highlight it as a strength at the end of the semester, as well as Figure $5 \mathrm{~A}$ and $\mathrm{B}$, where audience awareness came up a few times in the final reflections. They also began using different terms for writing as the semester progressed, characterizing what is part of "writing well" and using the terms we used in class and in feedback.

This focus on audience, process, and style also show up in the start of semester reflection for the seniors. While we don't analyze that data in this paper, a review of the seniors' responses shows that many of them bring up audience, clear/concise writing, use of active voice, and writing process (particularly revising and editing) in their start of semester reflection. While these seniors did not get a chance to reflect as much as the current juniors, their responses indicate that they too are learning the concepts we are targeting in instruction and are able to articulate them using a shared vocabulary.

For the juniors, the reflections provide the space for them to think back on their past learning and think ahead about what they want to do. By toggling between past and present, students are being asked to make connections on what they did and what they might do around writing. This progression from past attempts to future efforts may provide the space needed to apply learning. Furthermore, this progression also sends the message that writing is an iterative process, which means they do not need to be experts yet and that they can try, revise, and try again. As shown in Figure 6, they strongly believed that the focus on revision and the use of feedback was helpful to their writing, indicating that they not only understand the role of revision but actually tried to implement it as a process. This stance on writing as an iterative process may benefit students in a number of ways. One, they are able to understand that writing is less about inherent ability and 
more about practice. Two, this understanding could help them to feel less anxious about writing overall and thus more able to try approaches that would help them write effectively.

Additionally, students came to understand the benefits of having a process in mind when they worked. Many of the student comments focused on time management and needing sufficient time to be able to revise their work before submitting, indicating a stronger focus on process, particularly revision. They also began talking about revising as part of that process, including seeking out and receiving feedback from instructors and peers as they revised. This emphasis on process is visible in the two top goals for the spring semester: writing more concisely and using revision (see Figure 5B). Furthermore, as shown in Figure 6, students generally worked to use writing concepts, incorporate feedback, and focus on revising their work by the end of the semester. The students know revision is how they get at more effective writing, and the emphasis on process became clearer across the reflections.

This focus on process may hold potential for students to transfer writing learning into other learning spaces - and possibly beyond the university. Through use of various writing pedagogical methods in the class, including the reflections, it appears that we may be creating the conditions to not only improve writing within the class but also facilitate writing knowledge transfer. In writing studies scholarship, students focused on both writing process and practice [2]. Yancey, Robertson and Taczak purposefully designed a writing course for transfer that leveraged these two aspects of transfer, giving students the language and the tools to transfer both writing process and practice [2]. For process, understanding concepts and terms was an aspect of the course content and the focus of assignments as was having students reflect on their past experiences and project into the future [2].

For the materials science juniors, the focus on process as the semester progresses indicates that they are taking up those concepts and working with them. Since process was frequently the focus of lessons and conversations, the students knew it was important, so they knew to talk about it in the reflection. However, the data also show their use of the terms and concepts surrounding process were related to what they were actually doing or trying while writing. This focus would be a sign that we have begun creating the conditions for transfer, and offers some insight into pedagogical methods that work to encourage transfer.

Another element that impacts whether students are able to transfer knowledge is metacognition; thus, another question we wanted to answer was if students were showing signs of metacognition through the reflections. Again, the data shows some changes as the semester progresses and that the students may be displaying metacognition about their approaches to writing. For instance, their focus shifts from elements outside of a text at the start to what effective communication means at the end of the semester. Initially, students were talking in vague terms about writing well or communicating effectively, but by the end, they were using terms that would what it means to write effectively, specifically audience awareness (see Figures 4 and 5). They also came to define effective communication within the context of engineering as using clear, concise style and active voice, and a few talked about what "flow" meant in terms of connecting ideas and paragraphs. 
Furthermore, the writing related to the technical content and the writing may generate metacognition around the actual science the students were learning in class. One student remarked in the end of semester:

I wanted to focus on elaborating in the data analysis section. I feel that while I can usually get results, I do not always know what those results mean. I feel that with the writing feedback I got this semester, it forced me to ask more questions in class or during lab to gain a better understanding of what was going on, so that I could then add to my writing in a more clear and concise way.

While this was just one response, it indicates the benefits of sustained focus on writing and providing opportunities for reflection. This student not only began articulating their writing learning but also their overall learning through writing. This type of finding also points back to the benefits of the sustained collaboration between Jenn and Harold - we both embrace the understanding that writing and technical work in engineering are inseparable, and that core value is communicated to students. These students have the opportunity not only to learn technical concepts but to learn how to think about writing those concepts for a broader audience.

These data show promise in the use of reflection to support student learning in engineering courses. The reflections provide a space for students to examine and consider what they did and accomplished in the past and to reflect on what it might mean for future writing and work. Next steps will be to continue using reflections with the juniors and seniors and to determine what impact these reflections have on their growth and development as writers. If these reflections help create conditions for transfer, then these students will also enter the workplace as potentially more effective communicators.

\section{Conclusion}

A widely used tool in research and writing pedagogy, reflection offers potentials for the engineering classroom, particularly when one focus of the course is writing and communication. Not only do these reflections allow instructors to glimpse what students are thinking about as they write, but, more importantly, reflections also give students the space to look back on what they did and how they did it and to speculate about future work. And in an upper-level engineering course sequence, when combined with a sustained focus on writing and supported by faculty from both writing and engineering, reflections may create the conditions for successful transfer from junior to senior year and from college to beyond.

Future research will expand the work we discuss here and also refine the research methodology. For instance, the findings from this preliminary work can be used to refine the surveys to focus on or target certain concepts, such as having students select words from a list rather than an open-ended response. This focus will allow us to begin looking at transfer questions to see the ways their selections shift throughout the semester. While many of the open-ended questions will (and should) remain because it's the space where students do the intellectual work of reflecting, these assignments could be designed to more intentionally collect data that can answer questions about metacognition and/or transfer. This future research would contribute to both the engineering education and writing studies fields' understandings of what role reflection can play in teaching and research. 
Finally, we want to speculate about how this approach could be used elsewhere. The key elements are the sustained nature of this project; if Jenn were only to lecture in the class a few times, the impact on student learning would likely be less pronounced [21]. In addition to being embedded in the class, Jenn works closely with Harold to develop curriculum to provide opportunities to learn writing as part of student lab experiences. Together, we create the content around writing, from discussing what we think the students need and how we can respond to revising course materials to discussing the types of feedback we provide students and what we are seeing. We also use the data we collect to reflect and revise our own approaches, much like we ask students to reflect and revise in their writing. This model is part of what makes the collaboration successful and allows us to have a greater impact on student learning. Future work will explore the impacts of the nature of the partnership and how it can be built as a sustainable model.

Other programs seeking to apply our approaches in their program should begin by seeking out interested parties from across campus and inviting them to be partners in collaboration. The key term here is partner. If Jenn were not an active participant in the class and if her contributions were not as valued, the impact will likely not be the same. Indeed, part of what makes our work together successful is that Jenn is invested in the students' success; Jenn views them as her students as much as students in her technical communication courses. Furthermore, the MSE program supports this work through a course buyout and through other forms of monetary support. Other institutions have built similar collaborations, as Julie Ford discusses in several venues [21], [22]. Ford argues that because the mechanical engineering program initially created a joint appointment with English for her and then later housed her position completely, she was able to create a longer-lasting impact [22], and Jenn has found Ford's experience to apply to her work at Boise State.

Ultimately, these partnerships are deeply beneficial for the students because each party involved values the other's time, expertise, and knowledge. It shows a commitment to student learning, and it creates the support needed for a faculty member to cross disciplinary boundaries. From here, we will continue developing our approaches and seeking to evaluate student learning through these reflections and other pedagogical strategies. 


\section{References}

[1] M. Poe, N. Learner, and J. Craig. Learning to Communicate in Science and Engineering: Case Studies from MIT. Cambridge, MA: The MIT Press, 2010.

[2] K.B. Yancey, L. Robertson, and K. Taczak. Writing across Contexts: Transfer, Composition, and Sites of Writing. Boulder, CO: Utah State University Press, 2014.

[3] C. Kalman, M.W. Aulls, S. Rohar, and J. Godley, "Students' Perceptions of Reflective Writing as a Tool for Exploring an Introductory Textbook." Journal of College Science Teaching, pp. 74-81, March/April 2008

[4] C.S. Kalman, and S. Rohar, "Toolbox of Activities to Support Students in a Physics Gateway Course." Physics Education Research, vol. 6, no. 020111, pp. 1-15, 2010.

[5] V.A. Burrows, B. McNeill, N.F. Hubele, and L. Bellamy, "Statistical Evidence for Enhanced Learning of Content through Reflective Journal Writing." Journal of Engineering Education, vol. 90, no. 4, pp. 661-667, Oct. 2001.

[6] A. McKenna and A.M. Agogino. "Supporting Mechanical Reasoning in a RepresentationallyRich Learning Environment.” Journal of Engineering Education, vol. 93, no. 2, pp. 97-104, 2004.

[7] J.A. Turns, B. Sattler, K. Yashara, J.L. Borgford-Parnell, "Integrating Reflection into Engineering Education," in 121st ASEE Annual Conf. \& Exposition, Indianapolis, IN, 2014.

[8] K.L. Meyers, S.E. Silliman, N.L. Gedde, and M.W. Ohland. "A Comparison of Engineering Students' Reflections on Their First-Year Experiences." Journal of Engineering Education, vol. 99, no. 2, pp. 169-178, 2010

[9] D. Baker, S. Krause, S. Yaşar, C. Roberts, and S. Robertson-Kurpius. "An Intervention to Address Gender Issues in a Course on Design, Engineering, and Technology for Science Educators.” Journal of Engineering Education, vol. 96, no. 3, pp. 213-226, 2007.

[10] C.S. Lee, N.J. McNeil, E.P. Douglas, L.M.E. Koro, and D.J. Therriault. "Indispensable Resource? A Phenomenological Study of Textbook Use in Engineering Problem Solving." Journal of Engineering Education, vol. 102, no. 2, pp. 269-288, 2013.

[11] A.F. McKenna, B. Yalvac, G.J. Light. "The Role of Collaborative Reflection on Shaping Engineering Faculty Teaching Approaches." Journal of Engineering Education, vol. 98, no. 1, pp. 17-26, 2009.

[12] R.M. Felder, R. Brent, and M.J. Prince. "Engineering Instructional Development: Programs, Best Practices, and Recommendations." Journal of Engineering Education, vol. 100, no. 1, pp. 89-122, 2011. 
[13] Daly SR, Adams RS, Bodner GM. "What Does it Mean to Design? A Qualitative Investigation of Design Professionals' Experiences." Journal of Engineering Education, vol. 101, no. 2, pp. 187-219, 2012.

[14] K.L. Wood, D. Jensen, J. Bezdek, and K.N. Otto. "Reverse Engineering and Redesign: Courses to Incrementally and Systematically Teach Design." Journal of Engineering Education, vol. 90, no. 3, pp. 363-374, 2001.

[15] C.B. Zoltowski, W.C. Oakes, and M.E. Cardella. "Students Ways of Experiencing HumanCentered Design.” Journal of Engineering Education, vol. 101, no. 1, pp. 28-59, 2012.

[16] Boise State University First Year Writing Program. "Core Concepts for FYW." [Online]. Available: https://sites.google.com/a/boisestate.edu/fywp-quilt-project/core-concepts-for-fyw [Accessed Apr. 10, 2019].

[17] Boise State University Center for Teaching and Learning. "Center for Teaching and Learning Mission Statement." [Online]. Available: https://ctl.boisestate.edu/contact/missionstatement/ [Accessed Apr. 10, 2019].

[18] K.P. Alexander, "From Story to Analysis: Reflection and Uptake in the Literacy Narrative Assignment." Composition Studies, vol. 43, no. 2, pp. 43-71, 2015.

[19] K.B. Yancey. Reflection in the Writing Classroom. Logan, UT: Utah State University Press, 1998.

[20] V.J. Hsu. "Reflection as Relationality: Rhetorical Alliances and Teaching Alternative Rhetorics.” College Composition and Communication, vol. 70, no. 2, pp. 142-168, 2018.

[21] J.D. Ford. "Integrating Communication into Engineering Curricula: An Interdisciplinary Approach to Facilitating Transfer at New Mexico Institute of Mining and Technology." Composition Forum, no. 26, Fall 2012. [Online]. Available:

http://compositionforum.com/issue/26/new-mexico-tech.php [Accessed Apr. 10, 2019].

[22] J.D. Ford. "Going Rogue: How I Became a Communication Specialist in an Engineering Department.” Technical Communication Quarterly, vol. 27, no. 4, pp. 336-342, 2018. 
Appendix A: Reflection Questions--Juniors

\section{Overview Reflections}

Start of Semester Reflection

1. What are the top 1-3 writing concepts you think about or use when you write in materials science?

2. What are your strengths in writing?

3. What is currently your strengths in writing?

4. What is currently your greatest challenge when it comes to writing?

5. What are your goal(s) for this semester? (other than earning good grades)

6. What would help you best accomplish these goals? List anything, including your own efforts and additional resources that your instructors could provide.

End of Semester Reflection

1. Rate how the focus on writing helped in the following areas [ 1 not helpful at all to 5 very helpful]

a. Understanding of writing concepts

b. Understanding of technical content

c. Ability to revise your writing

d. Scores on written assignments

2. Rank the degree to which you incorporated feedback from previous writing assignments into subsequent writing assignments [1 not at all to $5 \mathrm{a}$ lot]

3. Rank your confidence with the following aspects of project reports [1 not confident at all to 5 very confident]

a. Abstract/project summary

b. Background/Introduction

c. Materials and Methods

d. Results and Discussion

e. Analyzing data

f. Preparing figures

g. Conclusions and recommendations

4. What are the top 1-3 writing concepts you learned or build on this semester?

5. What are your strengths in writing? What factored into your development of these strengths?

6. The start of semester reflection asked you to think about your greatest challenge regarding writing. Is that still a challenge, or has it changed? How did you tackle your writing challenges throughout the semester?

7. How do you plan to address these challenges in the spring semester?

8. What were your goal(s) for writing this semester? How did you meet them? (If not, how can you work on meeting them next semester?)

9. What are your writing goals for next semester?

10. What would you best accomplish these goals? List anything, including your own efforts and additional resources that your instructors could provide.

11. What did you learn about writing on teams this semester? Did you implement any of the recommendations [instructor] or the textbook provided? What worked well and what did not? 